\title{
As ZEIS e o reconhecimento dos territórios ocupados pela população de baixa renda: um estudo de caso do Bairro George Américo
}

\author{
MENEZES, José; FREIRE, Kayo; \\ Grupo Direito Territorialidade e Insurgência, Departamento de Ciências Sociais Aplicadas \\ Estudante do curso de Direito, UEFS, Feira de Santana - BA \\ kayomfreire@gmail.com
}

\section{Introdução}

Este trabalho teve como objetivo estudar o processo de ocupação e expansão do município de Feira de Santana, mais especificamente os processos que envolvem a disputa de luta pela efetivação do Direito à Moradia na formação do atual Bairro George Américo, maior ocupação do norte-nordeste na década de 70 .

Analisando um dos aspectos específicos do processo de aumento populacional de maneira desordenada, por meio de migração ou de êxodo rural (deslocamento da população da zona rural para a urbana), que gera uma realidade de periferização, deficit habitacional, encarecimento e escassez de serviços públicos, além de um tenso conflito entre os interesses de defesa ao direito à moradia, frente a intenção do capital imobiliário de lucrar com o desenvolvimento urbano.

No caso específico de Feira de Santana, há um aspecto diferente a se observar. Há por parte do poder público, principalmente nas décadas de 1970 e 1980, somado ao aumento da população urbana na cidade a tentativa de tentar ordenar a ocupação e produção desse espaço, essa ação se utiliza de programas de habitação social e regimes de mutirão para construção de casas, de sanar o problema do deficit habitacional da população mais pobre, ao mesmo tempo que a coloca em áreas distantes do centro urbano, o que para alguns pode ser tida como solução, para uma parte da população não é aceita, incitando os conflitos nesse campo.

Apesar de existir uma legislação extremamente progressista, trazendo conceitos importantes como o princípio da função social da propriedade, a prevalência do interesse coletivo sobre o individual, o próprio estatuto das cidades e outras normativas específicas sobre a gestão democrática, e os direitos sociais urbanos, na maior parte das cidades, inclusive Feira de Santana, tais instrumentos são subutilizados ou não utilizados. Essa forma excludente de planejar a cidade, termina criando conflitos urbanos desiguais na disputa de interesses entre as forças que desejam a garantia do direito social à moradia e as forças que anseiam o lucro em cima do processo de urbanização. 
Nessa perspectiva se insere a ocupação do campo de pouso (hoje bairro George Américo, Feira de Santana - BA), decorrido um processo de disputa, judicial, política e social. O movimento que de origem ao bairro (somado a diversas outras forças que participaram nesse processo), torna-se vitorioso, ao garantir às famílias que ali ocuparam, o direito a permanecer nessa importante área de vazio urbano na cidade de Feira de Santana. Uma ação conjunta de atores sociais, políticos e técnicos, tal processo de ocupação, dado o grau de organização continua apesar do passar dos anos sendo um importante exemplo de método de atuação e disputa bem sucedida de direitos na cidade.

\section{Materiais e métodos}

Para construção do presente trabalho, realizou-se um levantamento bibliográfico, com base em documentos oficiais, leis municipais, registros de jornais da época (como o Jornal Feira Hoje), releitura de materiais e artigos relacionados ao tema, os programas de habitação municipais (como o Programa Planolar e os Conjuntos habitacionais da URBIS), as legislações urbanas nacionais, e obras sobre o processo de desenvolvimento urbano do Brasil e da região nordeste (SANTOS, Milton, 1994), além do plano diretor de desenvolvimento urbano, lei de uso e ordenamento do solo e materiais relacionados.

Foram construídas em grupo de pesquisa discussões e mesas de debate sobre artigos específicos e livros em relação ao Direito à Cidade. Utilizando como base os conceitos de Direito à Cidade, construídos por Henri Lefebvre (1958) e os conceitos de dimensão espacial e geografia econômica de David Harvey, o conceito de urbanização proposto por Milton Santos e os textos de René Becker (2009), Gessiane Caldas (1998) e Nacelice Freitas (2004) sobre o processo de ocupação e de formação do espaço urbano além da importância do processo de industrialização na construção da malha urbana da cidade de Feira de Santana, além de outros conteúdos correlatos, sobre o processo de urbanização nesse Município.

\section{Resultados e discussão}

As ocupações urbanas são uma das ações mais enérgicas que toma a população, frente a falta ou inefetividade da resposta Estatal frente a falta de moradias, a ocupação do campo de pouso foi a maior ocupação urbana no norte-nordeste na década de 70 , tendo sido vitoriosa em uma ação conjunta integrada pela ação do elemento técnico ( $O$ escritório de Engenharia), político (a liderança compreendida pela figura de George Américo) e social (em atores como a Associação dos Sem Teto e o Movimento de organização comunitária MOC,. 
Esse tipo de disputa e resistência nem sempre acontecem pelas vias "legais", sendo a violência, a ameaça e a pressão psicológica, ferramentas amplamente utilizadas pelo poder público e capital imobiliário, na intenção de evitar a ocupação desse valioso espaço urbano, situado próximo ao anel de contorno e envolto de áreas já amplamente preenchidas. Nesse sentido ocorre processo de regularização fundiária do território, havendo a concessão de títulos aos habitantes.Essa formalização se deu pelos instrumentos jurídicos citados (Lei $n^{\circ}$ 2038 de dezembro de 1998 e o decreto 6.564 de 29 de abril de 2002) por meio do "Programa Morar Legal", por meio dos quais foram titulados os terrenos de mais de 500 famílias no local (de acordo com CALDAS, 1998 e SILVA, 2003), processo que apenas formaliza um direito já adquirido, proveniente da luta dessas famílias e do tensionamento criado pela ação da sociedade civil e o movimento social organizado.

A cidade de Feira de Santana porém ainda demonstra diversos desses problemas urbanos antigos já citados, a segregação espacial é clara na cidade, havendo grandes vazios urbanos e sendo a maior parte da população mais pobre habitante das áreas que estão dentro do anel de contorno de Feira (área historicamente ocupada pela população de melhor renda), oriundas de processos de ocupação, que sofrem com problemas como a falta ou insuficiência de serviços públicos e outros decorrentes da inação do Poder Público.

As ocupações urbanas apesar de não tão frequentes, ainda ocorrem em Feira de Santana, em espaços como o bairro Jussara(ocupação Sonho Real), além de diversas outras ocupações menores principalmente em áreas de lagoas, como a lagoa do Subaé, Lagoa Salgada no bairro homônimo ou a lagoa da Tábua no conjunto Feira VI, mostrando portanto que tais problemas sociais ainda persistem, e que as soluções apresentadas pelo poder público, mais de 40 anos depois da ocupação do que hoje é o Bairro George Américo, continuam ineficazes e incapazes de suprir a demanda da população, principalmente a mais carente pelo direito social a moradia.

\section{Referências}

Lei $n^{\circ}$ 1614, agosto de 1992. DISPÕE SOBRE O PLANO DIRETOR DE DESENVOLVIMENTO DO MUNICÍPIO DE FEIRA DE SANTANA, E DÁ OUTRAS PROVIDÊNCIAS. Disponível em:

$<$ https://leismunicipais.com.br/plano-diretor-feira-de-santana-ba> Acesso em: 30 de junho 2019.

Lei $n^{\circ}$ 825, de 15 de agosto de 1977. Cria o Plano Municipal de Habitação PopularPLANOLAR e a diretoria de habitação social, e dá outras providências. Disponível em: $<$ https://leismunicipais.com.br/a2/ba/f/feira-de-santana/lei-ordinaria/1977/83/825/lei-ordinaria- 
n-825-1977-cria-o-plano-municipal-de-habitacao-popular-planolar-e-a-diretoria-de-habitacaosocial-e-da-outras-providencias?q=825\%201977> Acesso em: 30 Junho de 2019.

Lei $N^{\circ}$ 2038, de 07 de dezembro de 1998. AUTORIZA O PODER EXECUTIVO A DOAR ÁREAS DE TERRA A PESSOAS FÍSICAS PARA FINS DE HABITAÇÃO. Disponível em: <https://leismunicipais.com.br/a/ba/f/feira-de-santana/lei-ordinaria/1998/204/2038/lei-ordinari a-n-2038-1998-autoriza-o-poder-executivo-a-doar-areas-de-terra-a-pessoas-fisicas-para-fins -de-habitacao-1998-12-07-versao-original> Acesso em: 30 junho de 2019.

CALDAS, Gessiane Oliveira. Espaços Urbanos - Uma Produção Popular - Qualificação e Requalificação do Bairro George Américo - Feira de Santana - Salvador - BA (1987 - 1998). Dissertação de Mestrado - Mestrado em Arquitetura e Urbanismo, na área de concentração em Desenho Urbano - Faculdade de Arquitetura e Urbanismo da Bahia (UFBA - Salvador, 1998).

SANTOS, Bethsaide Souza. Análise espacial da distribuição dos condomínios fechados na zona urbana de Feira de Santana entre 1995 e 2010. Monografia de Bacharel em Engenharia Civil (UEFS - Feira de Santana, 2012).

Associação Brasileira de Incorporadoras Imobiliárias - ABRAINC. Análise das Necessidades Habitacionais e suas Tendências para os Próximos Dez Anos. Relatório Técnico Final $2^{a}$ Versão (FGV Projetos, 2018)

SILVA, Elizemar Jesus T. A legalização fundiária dos assentamentos subnormais de Feira de Santana com foco no Bairro George Américo. Monografia de pós-graduação, na área de Gerenciamento da Construção Civil (UEFS - Feira de Santana, 2003).

FREITAS, Nacelice. Barbosa. Urbanização de Feira de Santana: influência da industrialização 1970 - 1996. Dissertação apresentada ao Mestrado em Arquitetura e Urbanismo da Universidade Federal da Bahia - UFBA, 1997.

Freitas, Nacelice. O Descoroamento da Princesa do Sertão: De "chão" A Território, o "Vazio" no Processo de Valorização do Espaço.". XI Encontro Nacional da Anpege. (São Paulo, 2015).

BECKER, René. A Urbanização e os Assentamentos Subnormais de Feira de Santana. Tese (Tese em Ciências Sociais) - (PUC. São Paulo, 2009).

SANTOS, Milton. A urbanização brasileira. Ed. 6. São Paulo, Editora da USP, 2005.

SANTO, Sandra Medeiros. A água em Feira de Santana: uma análise do bairro Rocinha. Dissertação (Programa de pós graduação em Arquitetura e Urbanismo) - (UFBA, Salvador, 1997). 